\title{
Salt tolerance of a wild ecotype of vetiver grass (Vetiveria zizanioides L.) in southern China
}

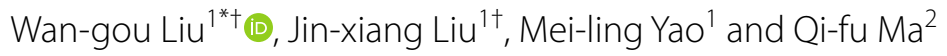

\begin{abstract}
Background: Vetiver grass (Vetiveria zizanioides L.) is widely used in more than 120 countries for land management (e.g. rehabilitation of saline lands). A wild ecotype of vetiver grass was found in southern China in the 1950s, but little is known about its adaptability to saline stress. For the purpose of understanding its tolerance to salinity as well as corresponding tolerance mechanisms, in a greenhouse with natural lighting, seedlings were grown in culture solutions and subjected to a range of $\mathrm{NaCl}$ concentrations for 18 days.

Results: Compared to no $\mathrm{NaCl}$ treatment, $200 \mathrm{mM} \mathrm{NaCl}$ significantly reduced leaf water potential, leaf water content, leaf elongation rate, leaf photosynthetic rate and plant relative growth rate and increased leaf malondialdehyde (MDA) content, but the parameters showed only slight reduction at $150 \mathrm{mM} \mathrm{NaCl}$. In addition, salinity caused an increase in the activity of antioxidant enzymes in leaves. Moreover, increasing $\mathrm{NaCl}$ levels significantly increased $\mathrm{Na}^{+}$ but decreased $\mathrm{K}^{+}$concentrations in both roots and leaves. The leaves had higher $\mathrm{K}^{+}$concentrations at all $\mathrm{NaCl}$ levels, but lower $\mathrm{Na}^{+}$concentrations compared to the roots, thereby maintaining higher $\mathrm{K}^{+} / \mathrm{Na}^{+}$ratio in leaves.

Conclusions: Our results showed that the salinity threshold of this wild vetiver grass is about $100 \mathrm{mM} \mathrm{NaCl}$, i.e. highly tolerant to salt stress. This wild vetiver grass has a high ability to exclude $\mathrm{Na}^{+}$and retain $\mathrm{K}^{+}$in its leaves, which is a critical strategy for salt tolerance.
\end{abstract}

Keywords: Wild vetiver grass (Vetiveria zizanioides L.), Salt stress, Water relation, Antioxidant enzymes, Photosynthetic rate, Growth

\section{Background}

Salinity is a one of the major environmental stress with over 800 million ha of land globally are salt-affected, causing great losses in agriculture productivity (Ledesma et al. 2016). One approach to increase the use of saline lands is to identify new plant species with salt tolerance. To date, biotechnology has not yet developed salt tolerant cultivars for agriculture use (Himabindu et al. 2016) probably for the reason that salt tolerance is a complex trait determined by many genes which interact strongly with environmental factors (Munns et al.

*Correspondence: liuwangou@163.com

†Wan-gou Liu and Jin-xiang Liu contributed equally to this work

1 Life Science and Technology School, Lingnan Normal University,

Zhanjiang 524048, People's Republic of China

Full list of author information is available at the end of the article
2012). Therefore, the development of salt tolerant plants depends mainly on screening plant species with high salt tolerance and understanding the tolerance mechanisms (Feng et al. 2014).

Vetiver grass (Vetiveria zizanioides L.) is a perennial graminaceous plant native to tropical and subtropical areas (Ghotbizadeh and Sepaskhah 2015). This species is distinguished by its strong and extensive root system which can descend $5 \mathrm{~m}$ under tropical conditions. The extensive, thick and deep root system with a tensile strength equal to $1 / 6$ th that of mild steel provides the plant with a superior advantage for adaptation to a wide range of ambient stresses, for example drought, flood, extreme temperatures, heavy metals, acidity and alkalinity, and salinity (Ghotbizadeh and Sepaskhah 2015; Truong et al. 2002; Zhou and Yu 2009). In rain-fed 
agriculture the deep-rooted perennial grasses in rotation with annual crops may help recover the balance between water use and rainfall, therefore, preventing rising water tables taking salts to the surface (Munns and Tester 2008). Vetiver grass is already widely used for saline land rehabilitation (Datta et al. 2011; Donjadee and Tingsanchali 2012).

Most vetiver genotypes flower but do not produce seeds. In Wuchuan County $\left(21^{\circ} 30^{\prime} \mathrm{N}, 110^{\circ} 50^{\prime} \mathrm{E}\right)$, Guangdong Province of China, a wild and fertile ecotype of vetiver grass was found in May, 1957 (Xia and Ao 1998). This vetiver community extended over an area of about 7000 ha in the 1950s, but has now completely disappeared in the wild due to land clearing. Fortunately, the germplasm of this species was introduced into the Grass Research Station of Lingnan Normal University in 2002 (Liu and Chen 2002) where it has since grown with the climatic conditions similar to that of its origin. The original community was located at an alluvial plain near the estuary of South China Sea, where the whole community was usually inundated during the rainy season (from April to September), but the ground water level sometimes might be $2 \mathrm{~m}$ deep during the dry seasons (from October to March) (Xia 2002). The repeated drying/ rewetting cycles would raise the salinity of soil, leading to an expectation of salt tolerance by this vetiver ecotype. However, there have been no detail studies about its physiological responses under different environmental stresses. Understanding the stress physiology of this vetiver ecotype would not only help describe its biological characteristics, but evaluate its potential for applications in land management.

Salinity influences plants in two ways: (1) high salinity in the soil make it more difficult for roots to extract water, and (2) high concentrations of salt within the plant can be toxic (Munns and Tester 2008). In response to salinity, plants have evolved various mechanisms to mitigate osmotic stress, such as by stomatal closure to reduce water loss, by exclusion of $\mathrm{Na}^{+}$from leaf to minimize the toxicity of $\mathrm{Na}^{+}$and by sequestration of $\mathrm{Na}^{+}$into root and leaf vacuoles to alleviate ionic stress to cytoplasm. The ability to exclude $\mathrm{Na}^{+}$and to maintain low tissue $\mathrm{Na}^{+}$/ $\mathrm{K}^{+}$ratio is an essential aid for plant salt tolerance (Munns et al. 2012). Moreover, salt stressed plants can synthesize antioxidants in cells such as superoxide dismutase (SOD), catalase (CAT) and various peroxidases (POD) as scavengers of reactive oxygen species (ROS) (Wang et al. 2014). Although vetiver grasses are widespread in saltaffected regions, only a few studies have reported that they are moderately salt tolerant (Cuong et al. 2015; Zhou and Yu 2009) and the underlying mechanism of salt tolerance in vetiver is still unclear. In this study, we treated a wild ecotype of vetiver grass from Wuchuan County with a range of $\mathrm{NaCl}$ levels to assess its capacity for salt tolerance in terms of water and ion relations, leaf gas exchange, plant growth and antioxidant enzyme activity. The possible mechanism of salt tolerance by this ecotype is discussed.

\section{Methods}

\section{Plant material and growth conditions}

Seeds of a wild ecotype of vetiver grass (Vetiveria zizanioides L.) were collected in October 2012 from the Grass Research Station of Lingnan Normal University, Zhanjiang, Guangdong province China $\left(20^{\circ} 55^{\prime} \mathrm{N}, 110^{\circ} 11^{\prime} \mathrm{E}\right)$. Its 1000 seed weight was $291 \mathrm{mg}$. Seeds were sown in soil in pots (18 cm high, $25 \mathrm{~cm}$ in diameter). Seven months after sowing, the seedlings (about $30 \mathrm{~cm}$ high) were transplanted into plastic buckets (depth $27.5 \mathrm{~cm}$, diameter $30 \mathrm{~cm}$ ) containing Hoagland solution $\left[2.5 \mathrm{mM} \mathrm{Ca}\left(\mathrm{NO}_{3}\right)_{2}\right.$, $2.5 \mathrm{mM} \mathrm{KNO}_{3}, 1 \mathrm{mM} \mathrm{MgSO}, 0.5 \mathrm{mM} \mathrm{KH}_{2} \mathrm{PO}_{4}, 45 \mu \mathrm{M}$ Fe-EDTA, $23 \mu \mathrm{M} \mathrm{H}_{3} \mathrm{BO}_{3}, 4.55 \mu \mathrm{M} \mathrm{MnSO}_{4}, 0.16 \mu \mathrm{M}$ $\mathrm{CuSO}_{4}, 0.38 \mu \mathrm{M} \mathrm{ZnSO}_{4}, 0.28 \mu \mathrm{M} \mathrm{H}_{2} \mathrm{MoO}_{4}$ ] and grown in a naturally-lit greenhouse. Nine months after sowing, uniform plants (about $60 \mathrm{~cm}$ high) were divided into four $\mathrm{NaCl}$ treatment groups (see below) with 60 plants per treatment, for a total of 240 plants. The plants were supported by a foam board while the roots were dipped into a $30 \mathrm{~L}$ Hoagland solution in a plastic container (length $50 \mathrm{~cm}$, width $38 \mathrm{~cm}$, depth $22.5 \mathrm{~cm}$ ), and 15 plants were grown in each container.

The salt treatments included $\mathrm{NaCl}$ levels of $0,100,150$ and $200 \mathrm{mM}$ and each treatment was replicated four times in a randomized block design. To avoid osmotic shock (Albert 1975), $\mathrm{NaCl}$ levels were increased by $50 \mathrm{mM}$ daily until the final levels of individual treatments were reached. The solutions were aerated for $2 \mathrm{~h}$ daily using aquatic pumps and replaced weekly. The $\mathrm{pH}$ of the nutrient solutions was adjusted to $6.5 \pm 0.1$ every day with $1 \mathrm{M} \mathrm{KOH}$ or $1 \mathrm{M} \mathrm{H}_{2} \mathrm{SO}_{4}$, as required. The experiment was completed after 18 days when plant growth was obviously suppressed by $200 \mathrm{mM} \mathrm{NaCl}$ but there was a lesser effect on plant by 100 and $150 \mathrm{mM} \mathrm{NaCl}$, compared with no $\mathrm{NaCl}$ treatment. At harvest, 15 plants in every container were composited as one replication, i.e. 60 plants in four replications for each $\mathrm{NaCl}$ treatment.

\section{Measurement of leaf gas exchange}

Before the plants were harvested for dry weight at the end of $\mathrm{NaCl}$ treatments, the third youngest fully expanded leaves were measured for net photosynthetic rate $\left(P_{n}\right)$, stomatal conductance $\left(g_{s}\right)$, transpiration rate $(E)$, and intercellular $\mathrm{CO}_{2}$ concentration $\left(C_{i}\right)$ with a portable photosynthesis system LI-6400XT (LI-COR Inc., Lincoln, NE, USA). Five random measurements of 15 plants per container were composited as one replicate, and four 
replicates were taken between 9:00 a.m. and 12:00 noon under the conditions of photosynthetically active radiation of $1600 \mu \mathrm{mol} \mathrm{m}^{-2} \mathrm{~s}^{-1}$ via internal light source, leaf temperature of $35 \pm 1{ }^{\circ} \mathrm{C}$, relative humidity of $60 \pm 5 \%$, and ambient $\mathrm{CO}_{2}$ concentration of $389 \mu \mathrm{mol} \mathrm{mol}^{-1}\left(C_{a}\right)$. The stomatal limitation value $\left(L_{s}\right)$ was calculated as: (Ma et al. 2012)

$$
L_{s}=1-C_{i} / C_{a} .
$$

\section{Water relation measurement}

At the end of $\mathrm{NaCl}$ treatment, leaf water potentials $\left(\psi_{w}\right)$ of the third youngest fully expanded leaves were measured from 15 plants per container as one replicate, with four replicates in each treatment. The measurements were taken using a pressure chamber (Model 1000, PMS Instrument, Albany, OR, USA) at the time 10:00-11:00 am.

After fresh weights (FW) of the roots and leaves were recorded, they were oven-dried at $105{ }^{\circ} \mathrm{C}$ for $15 \mathrm{~min}$ and then dried at $75{ }^{\circ} \mathrm{C}$ for $48 \mathrm{~h}$ and dry weights (DW) were recorded. Tissue water content $(W C)$ was calculated on a fresh weight basis,

$$
\mathrm{WC}(\%)=(\mathrm{FW}-\mathrm{DW}) / \mathrm{FW} \text {. }
$$

\section{Antioxidant enzyme activity assays}

About $0.5 \mathrm{~g}$ of the youngest fully expanded leaves were ground in liquid nitrogen with a mortar and homogenized in $1 \mathrm{~mL}$ of $50 \mathrm{mM}$ phosphate buffer ( $\mathrm{pH}$ 7.0) containing $3 \mu \mathrm{M}$ EDTA and $1 \%$ polyvinylpolypyrrolidone (PVP). The homogenates were centrifuged at $12,000 \mathrm{rpm}$ for $30 \mathrm{~min}$ at $4{ }^{\circ} \mathrm{C}$ and the supernatant was collected and used for antioxidant enzyme activity analysis.

Leaf SOD was measured through the inhibition of nitro blue tetrazolium (NBT) reduction with the $\mathrm{O}_{2}^{-}$generated by the xanthine oxidase system. One unit (U) of SOD was defined as the amount of enzyme required to inhibit NBT reduction by $50 \%$ under the assay conditions. The reduction of NBT was determined from an initial absorbance change using spectrophotometer at $560 \mathrm{~nm}$ after addition of xanthine oxidase at $25^{\circ} \mathrm{C}$. CAT activity was measured according to the method of Aebi (1984) by determination the disappearance of $\mathrm{H}_{2} \mathrm{O}_{2}$ by measuring the decrease in an absorbance at $240 \mathrm{~nm}$ of a reaction mixture containing $25 \mathrm{mM}$ phosphate buffer ( $\mathrm{pH}$ 7.8), $10 \mathrm{mM} \mathrm{H}_{2} \mathrm{O}_{2}$ and enzyme. One unit of CAT was defined as the amount of enzyme required to decrease absorbance by one per minute. POD activity was measured by the increase in absorbance at $470 \mathrm{~nm}$ due to guaiacol oxidation. The reaction mixture contained $25 \mathrm{mM}$ phosphate buffer $(\mathrm{pH}$ 6.0), $0.05 \%$ guaiacol, $10 \mathrm{mM} \mathrm{H}_{2} \mathrm{O}_{2}$ and enzyme. One unit of POD was defined as the amount of enzyme required to increase absorbance by one per minute. All the activities of SOD, CAT and POD were expressed as enzyme units in a dry weight basis $\left(\mathrm{U} \mathrm{g}^{-1} \mathrm{DW}\right)$. All the measurements were repeated four times.

\section{Lipid peroxidation assay}

Lipid peroxidation was determined by measuring malondialdehyde (MDA) formation using the thiobarbituric acid method (Tang 1999). The fourth top leaf samples $(1 \mathrm{~g})$ were ground in liquid nitrogen and homogenized into $10 \mathrm{~mL}$ of $10 \%$ trichloroaceticacid. After centrifugation at $4000 \mathrm{rpm}$ for $10 \mathrm{~min}, 2 \mathrm{~mL}$ of supernatant was combined with $2 \mathrm{~mL}$ of $0.6 \%$ thiobarbituric acid, heated in boil water for $15 \mathrm{~min}$ and cooled rapidly on ice. The mixture was then centrifuged at $4000 \mathrm{rpm}$ for $10 \mathrm{~min}$, and its absorbance was determined at 450, 532 and $600 \mathrm{~nm}$ with a UV-1600 spectrophotometer. The MDA concentration was estimated using the following formula, and MDA content was expressed in a dry weight basis (nmol g $\left.{ }^{-1} \mathrm{DW}\right)$.

$$
C(\mu \mathrm{M})=6.45\left(\mathrm{~A}_{532}-\mathrm{A}_{600}\right)-0.56 \mathrm{~A}_{450}
$$

\section{Growth measurement}

Before the commencement of the four $\mathrm{NaCl}$ treatments, the uppermost-leaf length $\left(\mathrm{L}_{0}\right)$ was measured and plant initial dry weight $\left(\mathrm{DW}_{0}\right.$, included shoot and root) was estimated by destructively oven-drying ten additional plants at $75^{\circ} \mathrm{C}$ for $48 \mathrm{~h}$. At the end of the $\mathrm{NaCl}$ treatments, the corresponding leaf length $\left(\mathrm{L}_{1}\right)$ was measured again and plants were oven-dried for dry weight $\left(\mathrm{DW}_{1}\right)$ by taking the average of 15 plants per container as one replicate.

Leaf elongation rate $\left(L E R, \mathrm{~mm} \mathrm{~d}^{-1}\right)$ was calculated using the formula, $\left(\mathrm{L}_{1}-\mathrm{L}_{0}\right) / t$, where $t$ is the time interval (days).

Relative growth rate $\left(R G R, \mathrm{mg} \mathrm{g}^{-1} \mathrm{~d}^{-1}\right)$ was calculated using the formula, $\left(\operatorname{lnDW}_{1}-\mathrm{nDW}_{0}\right) / t$, in which $t$ is the time interval (days) (Poorter 2001).

\section{Assay of $\mathrm{Na}^{+}$and $\mathrm{K}^{+}$}

The harvested plants were washed firstly with tap water and then distilled water, and the roots and leaves were separated. After oven-dried at $75^{\circ} \mathrm{C}$ for $48 \mathrm{~h}$, the samples were ground and passed through a $2-\mathrm{mm}$ mesh sieve. The concentrations of $\mathrm{Na}^{+}$and $\mathrm{K}^{+}$in leaves and roots were measured following the previous method (Song et al. 2009) with some modifications. In brief, $0.2 \mathrm{~g}$ samples were processed in a muffle oven at $200{ }^{\circ} \mathrm{C}$ for $30 \mathrm{~min}$ and then $550{ }^{\circ} \mathrm{C}$ for $24 \mathrm{~h}$, and the ash was dissolved in $0.2 \mathrm{~mL}$ of concentrated nitric acid. The volume of the extraction was adjusted to $100 \mathrm{~mL}$ with double distilled water, and the concentrations of $\mathrm{Na}^{+}$and $\mathrm{K}^{+}$were measured using a flame photometer (Flame Photometer 420, Sherwood Scientific Ltd, Cambridge, UK). The ability of ion selective transportation $\left(S_{k / N a}\right)$ was calculated from the following formula: (Zhou and $\mathrm{Yu}$ 2009) 


$$
S_{k / N a}=\left(\mathrm{K}^{+} / \mathrm{Na}^{+} \text {in leaf }\right) /\left(\mathrm{K}^{+} / \mathrm{Na}^{+} \text {in root }\right) .
$$

\section{Statistical analysis}

All data in response to four $\mathrm{NaCl}$ treatments were subjected to one-way analysis of variance. Treatment differences were determined by Duncan's multiple range test at $p<0.05$ level. The statistical analyses were conducted using SPSS18.0 for windows (SPSS Inc., Chicago, IL, USA).

\section{Results}

\section{Water relations}

After vetiver plants were treated with $\mathrm{NaCl}$ for 18 days, leaf water potentials $\left(\psi_{w}\right)$ and content $(W C)$ were similar among treatments of 0,100 and $150 \mathrm{mM} \mathrm{NaCl}$, but decreased significantly at $200 \mathrm{mM} \mathrm{NaCl}$ (Fig. 1A, B).

\section{Plant growth}

During the period of $\mathrm{NaCl}$ treatments, the uppermostleaf elongation rate $(L E R)$ increased slightly at $100 \mathrm{mM}$ $\mathrm{NaCl}$ (5.2\%) and $150 \mathrm{mM} \mathrm{NaCl}$ (9.6\%), but significantly decreased at $200 \mathrm{mM} \mathrm{NaCl}$ (48.7 \%) (Fig. 2A). Consistently, the relative growth rate $(R G R)$ was reduced by 1.3 , $9.7 \%$ at $100,150 \mathrm{mM} \mathrm{NaCl}$, respectively, and $200 \mathrm{mM}$

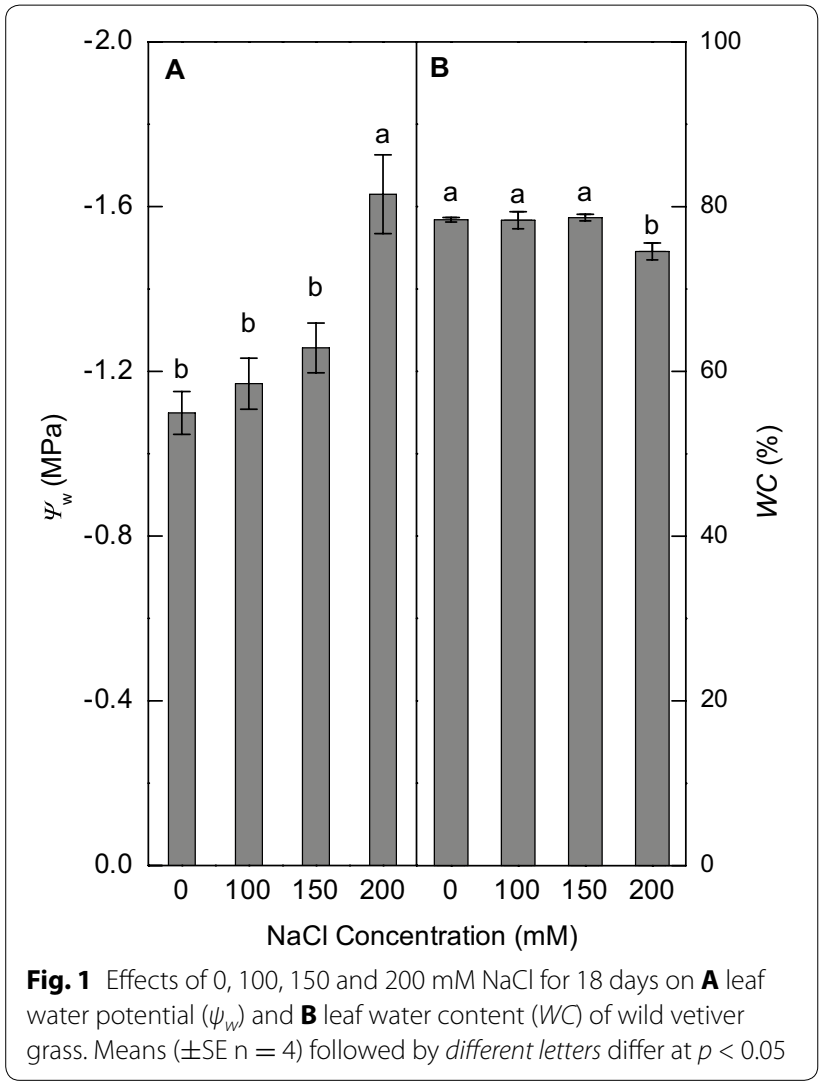

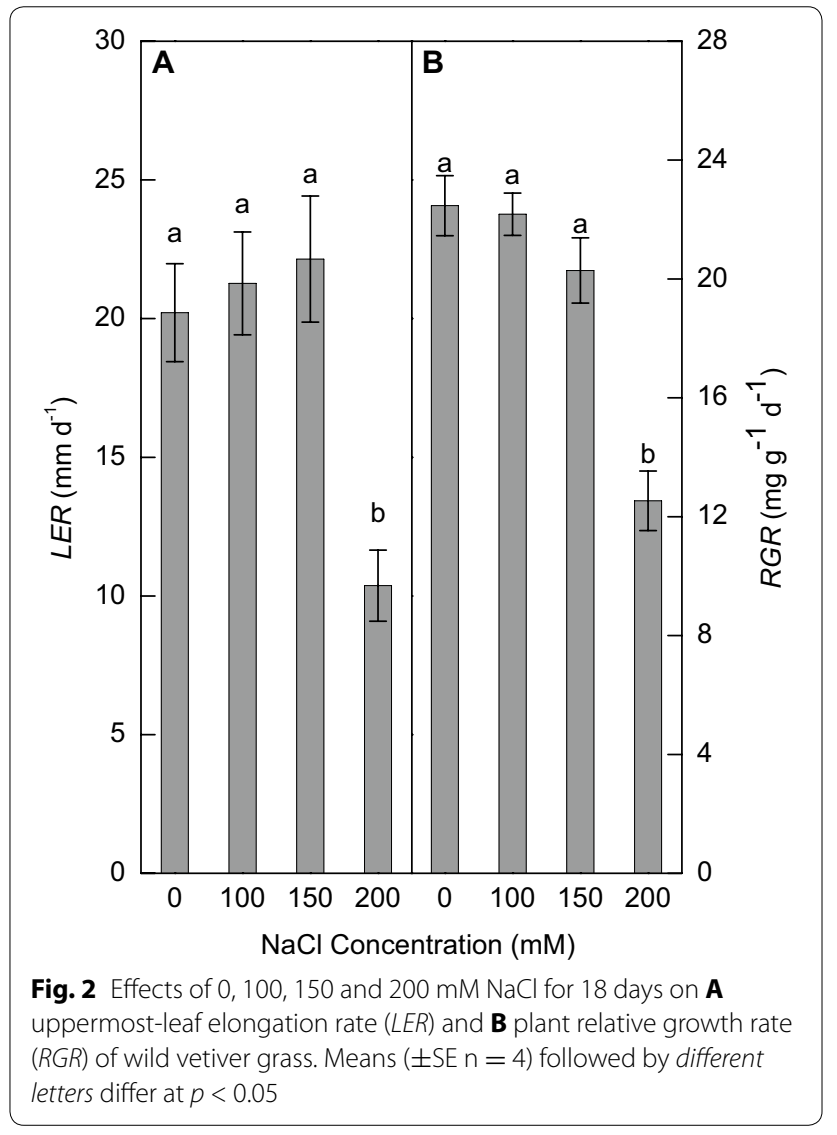

$\mathrm{NaCl}$ decreased $R G R$ by $44.2 \%(p<0.05)$ compared with the no $\mathrm{NaCl}$ treatment (Fig. 2B).

\section{Leaf gas exchange}

With increasing $\mathrm{NaCl}$ levels, leaf $P_{n}, g_{s}$ and $L_{s}$ declined and significant reduction was observed at $200 \mathrm{mM} \mathrm{NaCl}$ (Fig. 3A, B, E). Conversely, leaf $C_{i}$ was increased at 100 , 150 and $200 \mathrm{mM} \mathrm{NaCl}$ by $0.7,8.5$ and $25.4 \%$ respectively (Fig. 3C). Leaf $E$ was highest at $100 \mathrm{mM} \mathrm{NaCl}$ and slightly decreased at $150 \mathrm{mM} \mathrm{NaCl}$, but was significantly lowered at $200 \mathrm{mM} \mathrm{NaCl}$ (Fig. 3D).

\section{Antioxidant enzyme activities}

After $\mathrm{NaCl}$ treatments for 18 days, the activities of leaf POD at 100, 150 and $200 \mathrm{mM} \mathrm{NaCl}$ levels were significantly higher than at no $\mathrm{NaCl}$ level (Fig. 4A). In contrast, leaf CAT activities decreased with increasing $\mathrm{NaCl}$ levels, and significantly reduced at $200 \mathrm{mM} \mathrm{NaCl}$ (Fig. 4B). Although the peak SOD activity was observed at $100 \mathrm{mM}$ $\mathrm{NaCl}$, there were no significant differences among the $\mathrm{NaCl}$ treatments (Fig. 4C). Overall, this wild ecotype of vetiver grass maintained high activity of protective enzymes under saline condition. 


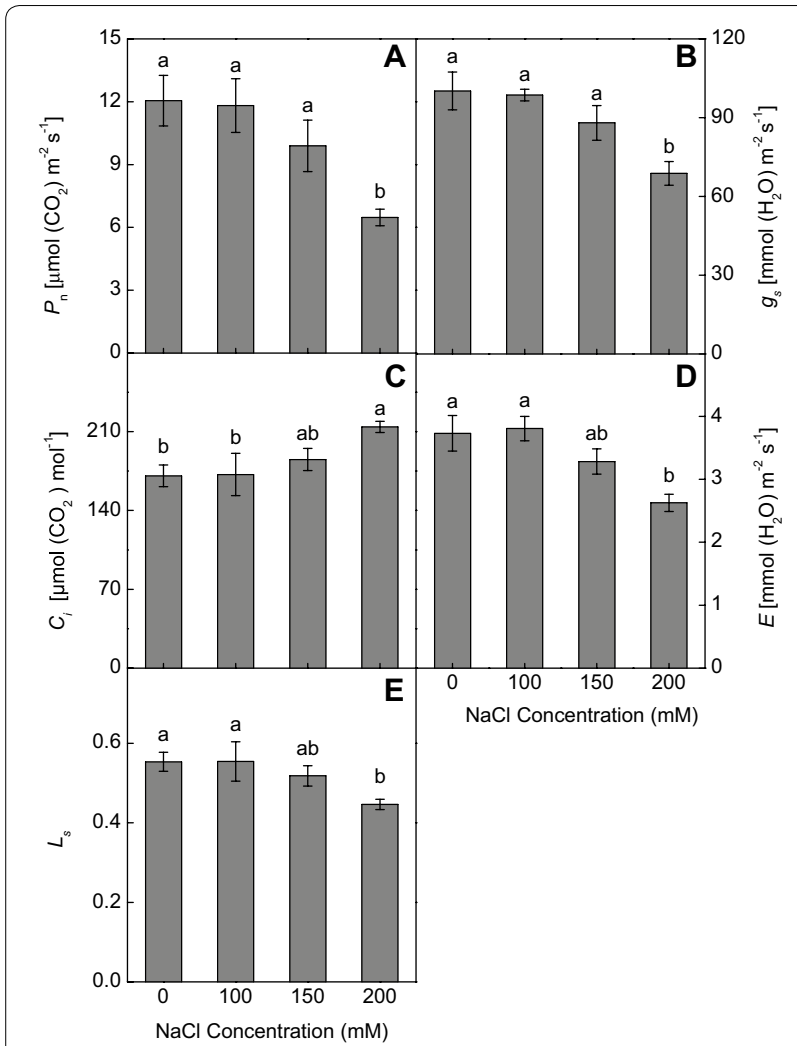

Fig. 3 Effect of $0,100,150,200 \mathrm{mM} \mathrm{NaCl}$ for 18 days on $\mathbf{A}$ the net photosynthetic rate $\left(P_{n}\right)$, B stomatal conductance $\left(g_{s}\right), \mathbf{C}$ intercellular $\mathrm{CO}_{2}$ concentration $\left(C_{j}\right)$, D transpiration rate $(E)$ and $\mathbf{E}$ stomatal limitation value $\left(L_{s}\right)$ of wild vetiver grass. Means $( \pm S E n=4)$ followed by different letters differ at $p<0.05$

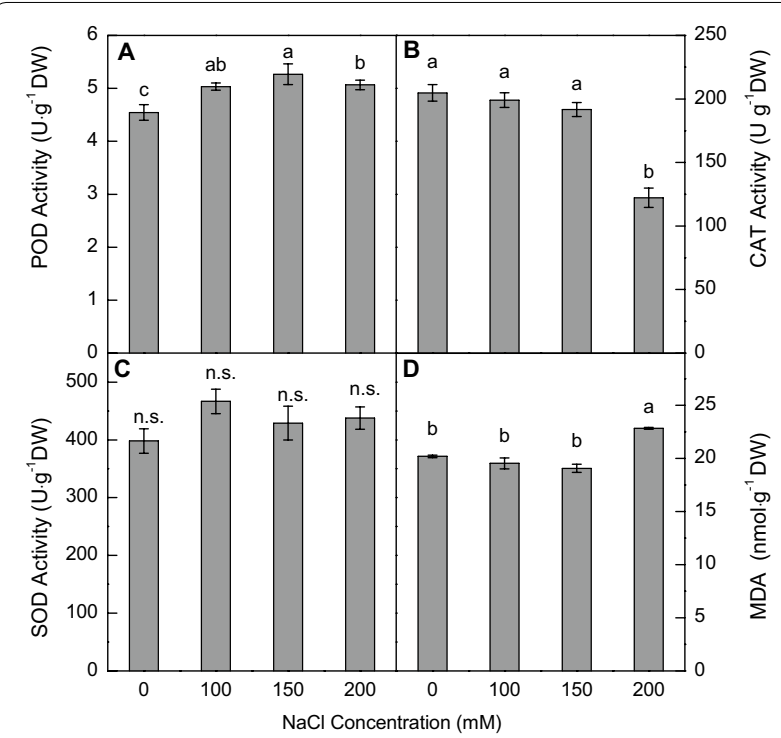

Fig. 4 Effects of 0, 100, 150, $200 \mathrm{mM} \mathrm{NaCl}$ for 18 days on A POD, B CAT, C SOD activities as well as $\mathbf{D}$ MDA content of wild vetiver grass. $n s$ no significance. Means ( \pm SE $n=4)$ followed by different letters differ at $p<0.05$ level

\section{MDA content}

Lipid peroxidation in leaves was responsive to $\mathrm{NaCl}$ levels, showing a significant increase at $200 \mathrm{mM} \mathrm{NaCl}$ but there were no significant changes at $100-150 \mathrm{mM} \mathrm{NaCl}$, compared with the no $\mathrm{NaCl}$ treatment (Fig. 4D).

\section{$\mathrm{Na}^{+}, \mathrm{K}^{+}$accumulation and ability of ion selective transportation $\left(\mathrm{S}_{\mathbf{k} / \mathrm{Na}}\right)$}

With increasing $\mathrm{NaCl}$ levels, wild vetiver plants significantly increased $\mathrm{Na}^{+}$concentration and decreased $\mathrm{K}^{+}$ concentration in the roots and leaves (Fig. 5A, B). The $\mathrm{Na}^{+}$concentration was higher in roots than in leaves at 100 and $150 \mathrm{mM} \mathrm{NaCl}$, but both roots and leaves had similar $\mathrm{Na}^{+}$concentrations at $200 \mathrm{mM} \mathrm{NaCl}$ (Fig. 5A). Across the $\mathrm{NaCl}$ treatments, root $\mathrm{K}^{+}$concentration was significantly lower than leaf $\mathrm{K}^{+}$concentration (Fig. 5B). The $\mathrm{Na}^{+} / \mathrm{K}^{+}$ratio in the roots and leaves increased with increasing $\mathrm{NaCl}$ levels, particularly in roots (Fig. 5C). Compared with the no $\mathrm{NaCl}$ treatment, the values of $S_{k}$ $\mathrm{Na}$ increased at 100 and $150 \mathrm{mM} \mathrm{NaCl}$ and reached the highest at $150 \mathrm{mM} \mathrm{NaCl}$, but decreased significantly at $200 \mathrm{mM} \mathrm{NaCl}$ (Fig. 5D).

\section{Discussion}

Plants sensitive or tolerant to salinity differ in the rate at which salt reaches toxic levels in leaves, and the time scale may be days or weeks depending on the species and the salinity level (Munns and Tester 2008). Vetiver grass (Vetiveria zizanioides L.), a perennial graminaceous plant, is commonly distributed in salt-affected regions, but little is known about the mechanism of its adaptation to salinity. In this study, we examined the salt tolerance of a wild and fertile ecotype of vetiver grass in southern China in terms of plant growth and physiological responses after exposure to a range of $\mathrm{NaCl}$ levels for 18 days. We found that this vetiver ecotype was highly tolerant to salinity with little adverse effect on plant growth at $100,150 \mathrm{mM} \mathrm{NaCl}$, which was probably achieved by a combination of $\mathrm{Na}$ exclusion and elevated activities of antioxidant enzymes in leaves.

\section{Growth response to salt stress}

Compared with no $\mathrm{NaCl}$ treatment, $200 \mathrm{mM} \mathrm{NaCl}$ for 18 days impaired leaf elongation (Fig. 2A) and photosynthesis (Fig. 3A) and reduced relative growth rate by about $44 \%$ (Fig. 2B). In contrast, plant growth was hardly affected by $150 \mathrm{mM} \mathrm{NaCl}$, and the treatments of 100 and $150 \mathrm{mM} \mathrm{NaCl}$ even had greater leaf elongation rate than no $\mathrm{NaCl}$ (Fig. 2A), suggesting that this wild and fertile ecotype has the ability to maintain plant growth and leaf elongation under highly saline conditions. In a previous study, addition of $100 \mathrm{mM} \mathrm{NaCl}$ stimulated both leaf and root growth of a vetiver cultivar (Vetiveria zizanioides L. 
Nash) (Karadge et al. 2011). These findings suggests that moderate $\mathrm{Na}^{+}$can be beneficial to the growth of vetiver grass, a common phenomenon reported in halophytes such as Atriplex nummularia (Tester and Davenport 2003) and also in glycophytes such as sugar beet (Wakeel et al. 2010) and barley (Ma et al. 2011), probably for the reason that $\mathrm{Na}^{+}$can substitute for non-specific biophysical functions of $\mathrm{K}^{+}$by maintaining cell turgor especially in stomatal guard cells and ionic balance (Kronzucker et al. 2013; Subbarao et al. 2003).

\section{Water relation, gas exchange and ion uptake}

High external salt concentrations of salts decrease the ability of roots to extract water and high concentrations of salts within the plant itself can be toxic, disturbing many physiological and biochemical processes (Munns and Tester 2008). In this study, leaf $\psi_{w}, W C$ (Fig. 1), and $P_{n}, g_{s}$ and $E$ (Fig. 3A, B, D) in vetiver grass was significantly suppressed by $200 \mathrm{mM} \mathrm{NaCl}$, which was consistent with previous reports in millet plants (Setaria italic L. and Panicum miliaceum L.) (Islam et al. 2011) and bread wheat (Triticum aestivum L.) (Kingsbury et al. 1984), but was largely not affected by $150 \mathrm{mM} \mathrm{NaCl}$.
The salt-induced osmotic stress would be the primary cause for lowered growth rate at $200 \mathrm{mM} \mathrm{NaCl}$. Under high salinity, once $\mathrm{Na}^{+}$has accumulated to toxic level in plants, plasma membrane depolarization occurs and activation of the outward $\mathrm{K}^{+}$channel can lead to high $\mathrm{Na}^{+}$/ $\mathrm{K}^{+}$ratio (Cuin and Shabala 2007) and ion-specific toxicity, particularly in leaves (Munns and Tester 2008). Tissue $\mathrm{K}^{+} / \mathrm{Na}^{+}$ratio is often regarded as a critical trait for salt tolerance in various plant species (Chen et al. 2007; de Souza Miranda et al. 2013; Hauser and Horie 2010; Munns et al. 2012). In this study, increasing $\mathrm{NaCl}$ levels increased $\mathrm{Na}^{+}$concentration but decreased $\mathrm{K}^{+}$concentration in the roots and leaves of vetiver grass. Moreover, the roots preferentially accumulated $\mathrm{Na}^{+}$at or below $150 \mathrm{mM} \mathrm{NaCl}$, while leaves preferentially accumulated $\mathrm{K}^{+}$at all $\mathrm{NaCl}$ levels (Fig. 5A, B). As a result, the $\mathrm{Na}^{+} / \mathrm{K}^{+}$ ratio in leaves was lowered at or below $150 \mathrm{mM} \mathrm{NaCl}$, but increased at $200 \mathrm{mM} \mathrm{NaCl}$ (Fig. $5 \mathrm{C}$ ). $\mathrm{High} \mathrm{Na}^{+} / \mathrm{K}^{+}$ratio disrupts ion homeostasis and damages plasma membranes (Deinlein et al. 2014). We found that although wild vetiver grass maintained high activity of antioxidant enzymes under saline conditions (Fig. 4), $200 \mathrm{mM}$ $\mathrm{NaCl}$ increased MDA production (Fig. 5), an indication

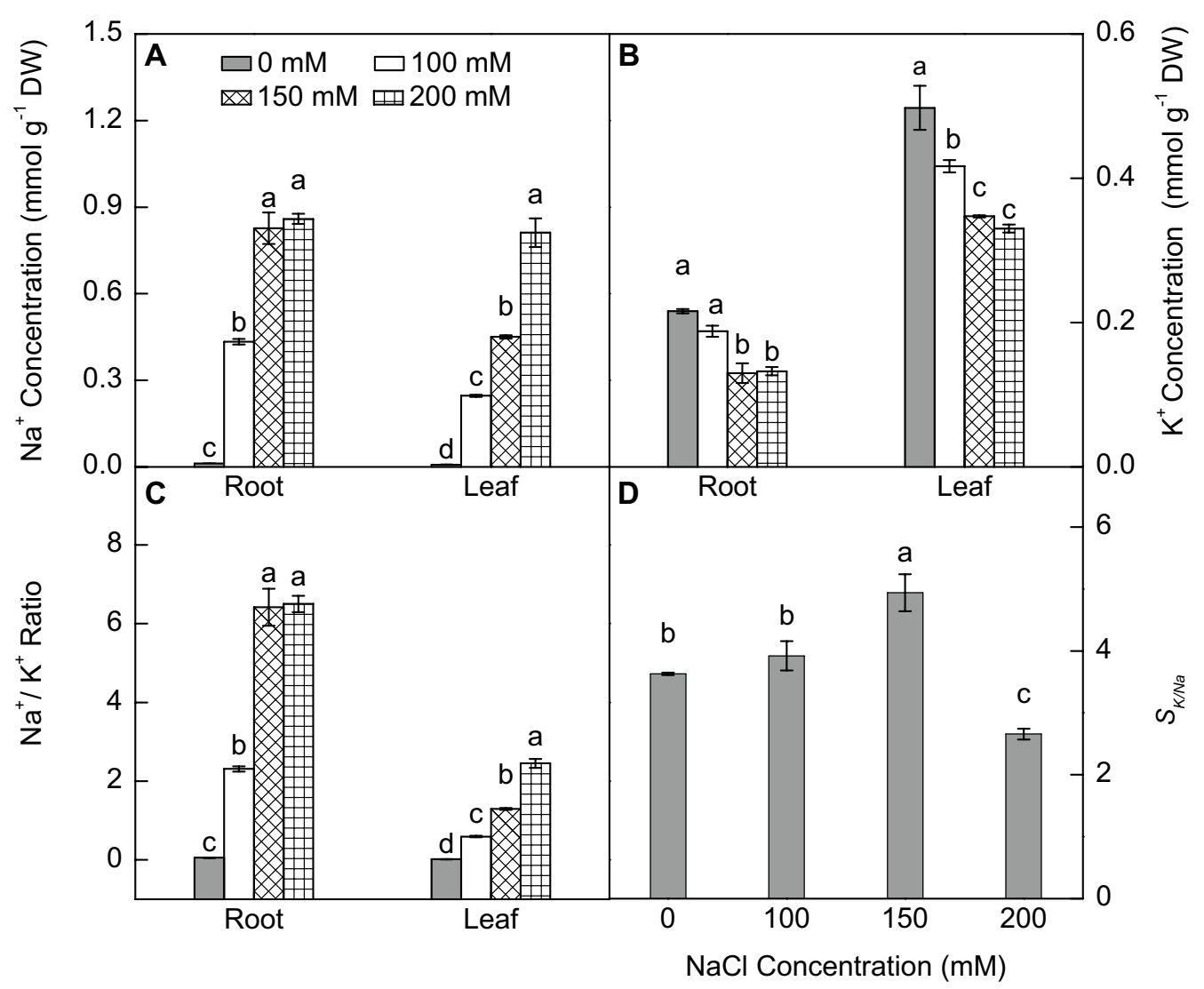

Fig. 5 Root and shoot $\mathbf{A ~ N a}{ }^{+}$concentration, $\mathbf{B} \mathrm{K}^{+}$concentration, $\mathbf{C ~ N a} / \mathrm{K}^{+}$ratio and $\mathbf{D}$ the ability of ion selective transportation $\left(S_{\mathrm{K} / \mathrm{Na}}\right)$ in wild vetiver seedlings treated with $0,100,150,200 \mathrm{mM} \mathrm{NaCl}$ for 18 days. Means $( \pm$ SE $n=4)$ followed by different letters differ at $p<0.05$ level 
of membrane damage. A similar finding was reported in barnyard grass (Echinochloa crusgalli L.) (Abogadallah et al. 2010). Low $P_{n}$ at $200 \mathrm{mM} \mathrm{NaCl}$ would be responsible for the increase in MDA through the formation of reactive oxygen species (ROS) which causes membrane lipid peroxidation (Carillo et al. 2011).

Excessive accumulation of $\mathrm{Na}^{+}$in leaves can also cause cation deficiency in $\mathrm{K}^{+}$for example, and inhibits photosynthesis (Gorai et al. 2010). In this study, $200 \mathrm{mM}$ $\mathrm{NaCl}$ significantly reduced leaf $P_{n}, g_{s}$ and $E$ in the wild vetiver grass (Fig. 3A, B, D). Leaf $L_{s}$, a parameter reflecting the degree of stomatal influence on photosynthesis under stress, also decreased with increasing $\mathrm{NaCl}$ levels (Fig. 3E), suggesting that the inhibited $P_{n}$ under salinity was mainly the result of non stomatal limitation.

\section{Salt tolerance}

According to USDA Salinity Laboratory, soils are classified as saline when saturation extract electrical conductivity (ECse) is $\geq 4 \mathrm{dS} \mathrm{m}^{-1}$ (equivalent to $40 \mathrm{mM} \mathrm{NaCl}$ ), which reduced the yield of most of crops. An ECse of $\geq 15 \mathrm{dS} \mathrm{m}^{-1}$ is considered highly saline (Munns 2005). Growth and physiological parameters can provide reliable criterions for evaluating salt stress or tolerance in plants (Huang et al. 2012; Munns 2005), including changes in length of a growing leaf, plant biomass and leaf stomatal conductance $\left(g_{s}\right)$ (Rozema and Flowers 2008). In this study $150 \mathrm{mM} \mathrm{NaCl}$ (i.e. $15 \mathrm{dS} \mathrm{m}^{-1}$ ) had no significant effect on leaf $g_{s}$ (Fig. 3B), LER and RGR (Fig. 2). In comparison, a previous report (Truong 1994) showed that vetiver grass had a salinity threshold of $8.0 \mathrm{dS} \mathrm{m}^{-1}$ and above the threshold yield reduction was $5.26 \%$ per unit $\mathrm{dS} \mathrm{m}^{-1}$. If the wild ecotype in this study had responded to salinity on a similar scale, its RGR would have reduced by 10,37 and $63 \%$ at 100, 150 and $200 \mathrm{mM} \mathrm{NaCl}$, respectively. In fact, we measured only 1.3, 9.7 and $44.2 \%$ reductions at the respective $\mathrm{NaCl}$ levels (Fig. 2B). The findings may suggest that the wild vetiver grass in southern China has salinity threshold of $\sim 10 \mathrm{dS} \mathrm{m}^{-1}$ and is more salt-tolerant than most of common vetiver varieties.

\section{Possible mechanisms of salt tolerance and prospect for application}

Leaves are the main site of $\mathrm{Na}^{+}$toxicity for most plants (Munns and Tester 2008), and therefore maintaining high $\mathrm{K}^{+} / \mathrm{Na}^{+}$ratio in leaves is essential for plant salt tolerance (Chinnusamy et al. 2005; Munns et al. 2012). Although high $\mathrm{K}^{+} / \mathrm{Na}^{+}$ratio could be obtained by exclusion of $\mathrm{Na}^{+}$from leaf or acceleration of $\mathrm{K}^{+}$entering into leaf, the ratio was mainly determined by leaf $\mathrm{Na}^{+}$status (Gorham et al. 1987). Increasing evidence indicates that the HKT genes are responsible for retrieval of $\mathrm{Na}^{+}$ from the xylem, i.e. the transpiration stream (Munns and Tester 2008). The value of ion selective transportation $\left(S_{k / N a}\right)$ is a good measure of retaining $\mathrm{Na}^{+}$in roots, i.e. higher $S_{k / N a}$ means greater $\mathrm{K}^{+} / \mathrm{Na}^{+}$discrimination in favor of $\mathrm{K}^{+}$against $\mathrm{Na}^{+}$accumulation in leaves. In this study, the $S_{k / N a}$ ratio increased at $100,150 \mathrm{mM} \mathrm{NaCl}$ and reached the highest at $150 \mathrm{mM} \mathrm{NaCl}$, indicating that salt tolerance in wild vetiver grass may be largely attributed to $\mathrm{Na}^{+}$exclusion from leaves (NEL) or $\mathrm{Na}^{+}$sequestration in roots. In contrast, previous soil column experiments suggested that high salt tolerance in vetiver was partly due to $\mathrm{Na}^{+}$avoidance by its deep rooting system (NAR) by escaping high salt in the surface soil (Truong 1994) or due to $\mathrm{Na}^{+}$exclusion by root (NER) (Xia et al. 2000).

In the NEL strategy this wild vetiver grass is able to retain a large fraction of $\mathrm{Na}^{+}$in the roots to alleviate the influence of $\mathrm{Na}^{+}$on salt-sensitive leaves, whereas in both NAR and NER strategies plants may exclude or avoid $\mathrm{Na}^{+}$from media around the roots. Undoubtedly, plants in the NEL strategy could absorb more salt from media than plants in the other strategies. Therefore, this wild vetiver grass may have a good prospect in phytoremediation of saline soil and saline water.

In conclusion, our results show that the salinity threshold of this wild vetiver grass is about $10 \mathrm{dS} \mathrm{m} \mathrm{m}^{-1}$, i.e. highly tolerant to salt stress. High ability of $\mathrm{K}^{+} / \mathrm{Na}^{+}$selective transportation in leaves may be the main strategy for salt tolerance by this wild ecotype of vetiver grass.

\section{Abbreviations \\ LER: leaf elongation rate; $R G R$ : relative growth rate; $\psi_{w}$ : water potential; WC: water content; $P_{n}$ : photosynthetic rate; $C_{j}$ intercellular $\mathrm{CO}_{2}$ concentration; $g_{5}$ : stomatal conductance; $E$ : transpiration rate; $\mathrm{C}_{a}$ : ambient $\mathrm{CO}_{2}$ concentration; $L_{s}$ : stomatal limitation value; POD: peroxidase; CAT: catalase; SOD: superoxide dismutase; MDA: malondialdehyde; $\mathrm{S}_{\mathrm{k} / \mathrm{Na}}$ : ion selective transportation.}

\section{Authors' contributions}

WGL designed the experiments. WGL, JXL and MLY performed the experiments. WGL and QFM analyzed the data and drafted the manuscript. All authors read and approved the final manuscript.

\section{Author details}

1 Life Science and Technology School, Lingnan Normal University, Zhanjiang 524048, People's Republic of China. ${ }^{2}$ School of Veterinary and Life Sciences, Murdoch University, 90 South Street, Murdoch, WA 6150, Australia.

\section{Acknowledgements}

The authors thank Ms. Patricia Graddy from Cary, North Carolina, USA for English editing. This work was supported by grants from Key project of natural science research of Lingnan Normal University (LZL1405), Guangdong science and technology planning projects (2016A040402046) and Zhanjiang key laboratory project of tropical plant resources and development (2014A06008).

\section{Competing interests}

The authors declare that they have no competing interests.

Received: 15 June 2016 Accepted: 2 October 2016

Published online: 06 October 2016 


\section{References}

Abogadallah GM, Serag MM, Quick WP (2010) Fine and coarse regulation of reactive oxygen species in the salt tolerant mutants of barnyard grass and their wild-type parents under salt stress. Physiol Plant 138:60-73. doi:10.1111/j.1399-3054.2009.01297.x

Aebi H (1984) Catalase in vitro. Methods Enzymol 105:121-126

Albert R (1975) Salt regulation in halophytes. Oecologia 21:57-71

Carillo P, Fuggi A, Pontecorvo G, Annunziata MG, Woodrow P (2011) Salinity stress and salt tolerance. INTECH Open Access Publisher, Rijeka, pp 22-38

Chen Z, Zhou M, Newman IA, Mendham NJ, Zhang G, Shabala S (2007) Potassium and sodium relations in salinised barley tissues as a basis of differential salt tolerance. Funct Plant Biol 34:150. doi:10.1071/fp06237

Chinnusamy V, Jagendorf A, Zhu JK (2005) Understanding and improving salt tolerance in plants. Crop Sci 45:437-448

Cuin TA, Shabala S (2007) Amino acids regulate salinity-induced potassium efflux in barley root epidermis. Planta 225:753-761. doi:10.1007/ s00425-006-0386-x

Cuong DC, Minh VV, Truong P (2015) Effects of sea water salinity on the growth of vetiver grass (Chrysopogon Zizanioides L.). In: 6th international conference on vetiver (ICV6) Da Nang, pp 1-10

Datta R, Quispe MA, Sarkar D (2011) Greenhouse study on the phytoremediation potential of vetiver grass, Chrysopogon zizanioides $L$., in arseniccontaminated soils. Bull Environ Contam Toxicol 86:124-128. doi:10.1007/ s00128-010-0185-8

de Souza Miranda R, Alvarez-Pizarro JC, Araújo CMS, Prisco JT, Gomes-Filho E (2013) Influence of inorganic nitrogen sources on $\mathrm{K}^{+} / \mathrm{Na}^{+}$homeostasis and salt tolerance in sorghum plants. Acta Physiol Plant 35:841-852. doi:10.1007/s11738-012-1128-2

Deinlein U, Stephan AB, Horie T, Luo W, Xu G, Schroeder JI (2014) Plant salt-tolerance mechanisms. Trends Plant Sci 19:371-379. doi:10.1016/j. tplants.2014.02.001

Donjadee S, Tingsanchali T (2012) Reduction of runoff and soil loss over steep slopes by using vetiver hedgerow systems. Paddy Water Environ 11:573-581. doi:10.1007/s10333-012-0350-2

Feng ZT, Deng YQ, Fan H, Sun QJ, Sui N, Wang BS (2014) Effects of NaCl stress on the growth and photosynthetic characteristics of Ulmus pumila L. seedlings in sand culture. Photosynthetica 52:313-320. doi:10.1007/ s11099-014-0032-y

Ghotbizadeh M, Sepaskhah AR (2015) Effect of irrigation interval and water salinity on growth of vetiver (Vetiveria zizanioides). Int J Plant Prod 9:17-38

Gorai M, Ennajeh M, Khemira H, Neffati M (2010) Influence of NaCl-salinity on growth, photosynthesis, water relations and solute accumulation in Phragmites australis. Acta Physiol Plant 33:963-971. doi:10.1007/ s11738-010-0628-1

Gorham J, Hardy C, Wyn Jones RG, Joppa LR, Law CN (1987) Chromosomal location of a $\mathrm{K} / \mathrm{Na}$ discrimination character in the $\mathrm{D}$ genome of wheat. Theor Appl Genet 74:584-588. doi:10.1007/BF00288856

Hauser F, Horie T (2010) A conserved primary salt tolerance mechanism mediated by HKT transporters: a mechanism for sodium exclusion and maintenance of high $\mathrm{K}^{+} / \mathrm{Na}^{+}$ratio in leaves during salinity stress. Plant Cell Environ 33:552-565. doi:10.1111/j.1365-3040.2009.02056.x

Himabindu Y, Chakradhar T, Reddy MC, Kanygin A, Redding KE, Chandrasekhar T (2016) Salt-tolerant genes from halophytes are potential key players of salt tolerance in glycophytes. Environ Exp Bot 124:39-63. doi:10.1016/j. envexpbot.2015.11.010

Huang Z, Long X, Wang L, Kang J, Zhang Z, Zed R, Liu Z (2012) Growth, photosynthesis and $\mathrm{H}^{+}$-ATPase activity in two Jerusalem artichoke varieties under NaCl-induced stress. Process Biochem 47:591-596. doi:10.1016/j. procbio.2011.12.016

Islam MS, Akhter MM, El Sabagh A, Liu LY, Nguyen NT, Ueda A, Masaoka Y, Saneoka H (2011) Comparative studies on growth and physiological responses to saline and alkaline stresses of Foxtail millet (Setaria italica L.) and Proso millet (Panicum miliaceum L.). Aust J Crop Sci 5:1269-1277

Karadge B, Samant J, Mane A, Saratale G (2011) Studies on the effects of salinity on growth, polyphenol content and photosynthetic response in Vetiveria zizanioides (L.) Nash. Emir J Food Agric 23:59-71
Kingsbury RW, Epstein E, Pearcy RW (1984) Physiological responses to salinity in selected lines of wheat. Plant Physiol 74:417-423

Kronzucker HJ, Coskun D, Schulze LM, Wong JR, Britto DT (2013) Sodium as nutrient and toxicant. Plant Soil. doi:10.1007/s11104-013-1801-2

Ledesma F, Lopez C, Ortiz D, Pengyin C, Korth KL, Tetsuaki I, Zeng A, Orazaly M, Florez-Palacios L (2016) A simple greenhouse method for screening salt tolerance in soybean. Crop Sci 56:585-594. doi:10.2135/ cropsci2015.07.0429

Liu JX, Chen Y (2002) Issues of utilization and protection for native Vetiver grass. Pratacultural Sci 17:13-16 (in Chinese)

Ma Q, Bell R, Brennan R (2011) Moderate sodium has positive effects on shoots but not roots of salt-tolerant barley grown in a potassium-deficient sandy soil. Crop Pasture Sci. doi:10.1071/CP11162

Ma Q, Yue LJ, Zhang JL, Wu GQ, Bao AK, Wang SM (2012) Sodium chloride improves photosynthesis and water status in the succulent xerophyte Zygophyllum xanthoxylum. Tree Physiol 32:4-13. doi:10.1093/treephys/ tpr098

Munns R (2005) Genes and salt tolerance: bringing them together. New Phytol 167:645-663. doi:10.1111/j.1469-8137.2005.01487.x

Munns R, Tester M (2008) Mechanisms of salinity tolerance. Annu Rev Plant Biol 59:651-681. doi:10.1146/annurev.arplant.59.032607.092911

Munns R, James RA, Xu B, Athman A, Conn SJ, Jordans C, Byrt CS, Hare RA, Tyerman SD, Tester M, Plett D, Gilliham M (2012) Wheat grain yield on saline soils is improved by an ancestral $\mathrm{Na}^{+}$transporter gene. Nat Biotechnol 30:360-364. doi:10.1038/nbt.2120

Poorter L (2001) Light-dependent changes in biomass allocation and their importance for growth of rain forest tree species. Funct Ecol 15:113-123

Rozema J, Flowers T (2008) Crops for a salinized world. Science 322:1478-1480. doi:10.1126/science.1168572

Song J, Chen M, Feng G, Jia Y, Wang B, Zhang F (2009) Effect of salinity on growth, ion accumulation and the roles of ions in osmotic adjustment of two populations of Suaeda salsa. Plant Soil 314:133-141. doi:10.1007/ s11104-008-9712-3

Subbarao GV, Ito O, Berry WL, Wheeler RM (2003) Sodium—a functional plant nutrient. Crit Rev Plant Sci 22·391-416. doi:10.1080/07352680390243495

Tang ZC (1999) Manual of plant physiology. Science Press, Beijing, pp 305-306 (in Chinese)

Tester M, Davenport R (2003) $\mathrm{Na}^{+}$tolerance and $\mathrm{Na}^{+}$transport in higher plants. Ann Bot 91:503-527

Truong P (1994) Vetiver grass, its potential in the stabilisation and rehabilitation of degraded saline land. In: Halophytes as a resource for livestock and for rehabilitation of degraded lands. Kluwer Academic Publishers, Berlin, pp 293-296

Truong P, Gordon I, Armstrong F, Shepherdson J (2002) Vetiver grass for saline land rehabilitation under tropical and Mediterranean climate. In: Eighth national conference productive use of saline lands, Perth, Australia

Wakeel A, Steffens D, Schubert S (2010) Potassium substitution by sodium in sugar beet (Beta vulgaris) nutrition on K-fixing soils. J Plant Nutr Soil Sci. doi:10.1002/jpln.200900270

Wang H, Xiao X, Yang M, Gao Z, Zang J, Fu X, Chen Y (2014) Effects of salt stress on antioxidant defense system in the root of Kandelia candel. Bot Stud 55:1-7. doi:10.1186/s40529-014-0057-3

Xia HP (2002) Natural vetiver communities distributed in China. Far East Agric 3-4:18-22

Xia HP, Ao DX (1998) Wild vetiver grass distributed in China and its protection and taxonomic problems. Chin Biodivers 6:292-297 (in Chinese)

Xia HP, Liu SZ, Ao DX (2000) Comparative study on salt resistance of Vetiveria zizanioides, Paspalum notatum and Alternanthera philoxeroides. Chin J Appl Environ Biol 6:7-17 (in Chinese)

Zhou Q, Yu BJ (2009) Accumulation of inorganic and organic osmolytes and their role in osmotic adjustment in $\mathrm{NaCl}$-stressed vetiver grass seedlings. Russ J Plant Physiol 56:678-685. doi:10.1134/s1021443709050148 